\title{
Antidiabetic Activity of Zingiber officinale Roscoe Rhizome Extract: an In Vitro Study
}

\author{
Kusumarn Noipha ${ }^{1 *}$, Putrada Ninla-Aesong ${ }^{2}$ \\ ${ }^{1}$ Faculty of Health and Sports Science, Thaksin University, Phatthalung, Thailand \\ ${ }^{2}$ School of Medicine, Walailak University, Nakhonsithammarat, Thailand
}

\section{ARTICLE INFO}

Article history:

Received December 19, 2017

Received in revised form September 5, 2018

Accepted September 21, 2018

\section{KEYWORDS:}

Ginger,

Glucose uptake,

GLUT1,

PI3-kinase,

AMPK

\begin{abstract}
The potential roles of Zingiber officinale Roscoe (ginger) for treating and preventing diabetes have been investigated in both humans and experimental animals. However, the mode of its action has not yet been elucidated. This study aimed to investigate the effects of ginger extract on glucose uptake activity and its activation pathway in L6 myotubes. Cells were co-cultured for $24 \mathrm{~h}$ with a variable concentration of either ginger extract or $2 \mathrm{mM}$ metformin or $200 \mathrm{nM}$ insulin or $20 \mu \mathrm{M}$ Troglitazone (TGZ), followed by a 10 -min $2-\left[{ }^{3} \mathrm{H}\right]$-deoxy-D-glucose (2-DG) uptake. The levels of glucose transporters 1 (GLUT1) and GLUT4 protein and mRNA expression were determined. Ginger extract at $400 \mu \mathrm{g} / \mathrm{ml}$ significantly enhanced glucose uptake in L6 myotubes $(208.03 \pm 10.65 \%$ above basal value, $\mathbf{p}<0.05$ ) after co-culture for $24 \mathrm{~h}$. The ginger-enhancement of glucose uptake was inhibited by $3.5 \mu \mathrm{M}$ cycloheximide, a protein synthesis inhibitor, $1 \mu \mathrm{M}$ wortmannin (Phosphatidylinositol 3-Kinase (PI3 kinase) inhibitor) and $15 \mathrm{nM}$ rapamycin (mammalian target of rapamycin (mTOR) inhibitor). The enhancement of glucose transport by ginger extract at $400 \mu \mathrm{g} / \mathrm{ml}$ was accompanied with the increased expression of GLUT1 protein $(1.60 \pm 0.20,2.03 \pm 0.19$, and $2.25 \pm 0.35$ folds of basal at 4,8 , and $24 \mathrm{~h}$, respectively $\mathrm{p}<0.05)$ and mRNA $(1.22 \pm 0.96,1.45 \pm 0.93,1.91 \pm$ $0.75,2.32 \pm 0.92$, and $2.20 \pm 0.64$ folds of basal at $1,2,4,8$, and $24 \mathrm{~h}$, respectively $\mathbf{p}<0.05$ ) in a time-dependent manner. $Z$. officinale Roscoe rhizome extract increase glucose transport activity of L6 myotubes by enhancing GLUT1 expression, the results of PI3-Kinase and 5'-AMP-activated kinase (AMPK) stimulation.
\end{abstract}

\section{Introduction}

Diabetes mellitus is one of the most prevalent and serious metabolic diseases and the principal cause of morbidity and mortality in the human. In diabetes, there is a failure to increase glucose uptake into peripheral tissues in response to insulin, leading to chronically elevated levels of glucose in the circulation (Dohm et al. 1988). A focus of current anti-diabetic medicine research is the development and screening of compounds with potential insulinomimetic effects to stimulate rate of cell glucose uptake (Ball et al. 2002).

Ginger (Z. officinale Rosoce, Zingiberaceae) is widely used spice and functional food. The medicinal properties attributed to ginger include antioxidant activity (Mojani et al. 2014), anti-arthritic (Shen et

\footnotetext{
* Corresponding Author

E-mail Address: kusumarn.n@hotmail.com
}

al. 2005), anti-inflammatory, and analgesic activities (Thomson et al. 2002; Ojewole 2006), anti-migraine (Mustafa and Srivastava 1990), anti-thrombotic (Thomson 2002), anti-cancer properties (Shukla and Singh 2007), hypolipidaemic and hypocholesterolaemic (Al-Amin 2006; Bhandari et al. 2005). A few isolated studies about the hypoglycemic properties of ginger in animals have reported variable results. In a study with diabetic rats, treatment with juice of ginger produced a significant increase in insulin levels and a decrease in fasting glucose levels in STZ-induced diabetic rats. In an oral glucose tolerance test, treatment with $Z$. officinale was found to decrease significantly the area under the curve (i.e. the extent of absorption) of glucose and to increase the area under the curve of insulin in Streptozotocin (STZ)-diabetic rats (Akhani et al. 2004). Insulin sensitivity improvement after ginger treatment was determined by Goyal and Kadnur (2006). Methanol and ethyl acetate extracts of ginger were administered for 8 weeks to mice and found 
that the treatment reduced goldthioglucose-induced obesity in the treated mice, and further reduced the elevated glucose and insulin levels. The recent report by Al-Amin and colleague (2006) confirmed that raw ginger possesses hypoglycemic, hypocholesterolemic and hypolipidemic potential. The ginger treatment also resulted in a significant reduction in urine protein levels (Al-Amin 2006).

Although a hypoglycemic effect of $Z$. officinale extract has been reported, the exact mechanism of this effect has yet to be elucidated. To gain understanding of the anti-diabetic properties of $Z$. officinale, we investigated the biological activity of $Z$. officinale on glucose transport in L6 myotubes and its downstream regulatory mechanism via the insulin signaling glucose transport pathways.

\section{Materials and Methods}

\subsection{Preparation of Ginger Extract}

Fresh Z. officinale rhizome was purchased local market of Songkhla, Thailand. The ginger roots were peeled and $100 \mathrm{~g}$ ginger were cut into small pieces and homogenized in $200 \mathrm{ml}$ distilled-water. The homogenization was carried out in a blender. The homogenized mixture was filtered three times through cheesecloth (very little material was retained on the cheesecloth). The filtrate was centrifuged at 800 $\mathrm{x} g$ for $10 \mathrm{~min}$ before lyophilization and the resulting residue $(2.5 \pm 0.9 \%$ yield $)$ was stored at $-70^{\circ} \mathrm{C}$ until use. Ginger extracts were used for determination of total phenolic content, active compound, toxicity and antidiabetic activity.

\subsection{Determination of Total Phenolic Content}

Total phenolic content was determined by the Folin-Ciocalteu method (Miliauskus et al. 2004) using gallic acid and tannic acid as a standard. $50 \mu \mathrm{l}$ of supernatant of ginger extract were mixed with $1,800 \mu \mathrm{l}(1 / 18$ dilution) of Folin-Ciocalteu reagent. They incubated at room temperature for around 10 minute. $300 \mu$ of the $20 \%$ sodium carbonate $\left(\mathrm{Na}_{2} \mathrm{CO}_{3}\right)$ solution was then added. The above solution was then kept in a dark place at room temperature for 2 hours. Absorbance was measured at $725 \mathrm{~nm}$. Phenolic content of the extracts was compared against gallic and tannic acid standard calibration curve. Total phenolic content was expressed as $\mathrm{mg}$ of gallic acid or tannic acid/g of dry weight of ginger rhizome.

\subsection{Determination of Active Compounds Content}

The contents of 6-gingerol, 6-shogoal, and zingerone were analyzed by high performance liquid chromatography (HPLC 1100, Agilent, Germany) equipped with a reversed phase column C18 (Hypersil ${ }^{\circledR}$ ODS 250 x $4.0 \mathrm{~mm}$ i.d., $5 \mu \mathrm{m}$ ), Elution was isocratic using a mixture of HPLC grade acetonitrile and water $(55: 45 \mathrm{v} / \mathrm{v})$ flow rate $1.0 \mathrm{ml} / \mathrm{min}$, temperature $30^{\circ} \mathrm{C}$. Detector was the Variable Wavelength Detector (VWD) set at $282 \mathrm{~nm}$. The compound was identified and quantified based on retention time using [6]-gingerol as HPLC external standard. $100 \mathrm{mg}$ of freeze dried of fresh juice ginger (FJG) extract were dissolved with $1 \mathrm{ml}$ methanol (HPLC grade) and centrifuged at 5,000 rpm for $5 \mathrm{~min}$. The supernatant was subsequently filtered through a $0.20 \mu \mathrm{m}$ Nylon membrane filter (Whatman, England). A $20 \mu$ l ginger extract was subjected into HPLC for the [6]-gingerol analysis.

\subsection{Culture of L6 Cells}

The rat L6 skeletal muscle cell line (ATCC, CRL1458 ) was maintained in $\alpha$-MEM containing $10 \%$ fetal bovine serum (FBS) and 1\% antibiotic solution (penicillin-streptomycin) in $10-\mathrm{cm}$ dishes (Corning, USA) in an atmosphere of $5 \% \mathrm{CO}_{2}$ at $37^{\circ} \mathrm{C}$, as reported by Klip (1984). L6 cells were rendered quiescent in $\alpha$-MEM containing $2 \%$ HS for 7-8 days to promote fusion into myotubes. The percentage of myotubes formation was determined as the percentage of nuclei present in multinucleated myotubes by phase-contast microscopy. In the present experiment, $80-90$ of myoblasts fused into myotubes.

\subsection{Cytotoxicity Assays}

Cell viability was assessed by sulforhodamine B (SRB) assay (Papazissis et al. 1997), lactate dehydrogenase (LDH) leakage was measured using LDH cytotoxicity detection kit (Roche) and MTT assay was used for assessing cell metabolic activity.

\subsection{Measurement of 2-Deoxy- $\left[{ }^{3} \mathrm{H}\right]-$ Glucose Uptake}

2-Deoxy-[ $\left.{ }^{3} \mathrm{H}\right]$-glucose uptake (2-DG) transport studies were performed on differentiated L6 cells as previously described (Noipha et al. 2008). The myotubes were grown in 24-well plates (Corning, USA) and after the indicated periods of incubation, the cells were then rinsed with HEPES- buffered saline solution (HBS; $140 \mathrm{mM} \mathrm{NaCl}, 5 \mathrm{mM} \mathrm{KCl}, 20 \mathrm{mM}$ HEPES, $205 \mathrm{mM}$ $\mathrm{MgSO}_{4}$, and $\left.1 \mathrm{mM} \mathrm{CaCl}, \mathrm{pH} 7.4\right)$. The $10 \mu \mathrm{M}$ 2-deoxy$\left[{ }^{3} \mathrm{H}\right]$-glucose $(1 \mu \mathrm{Ci} / \mathrm{ml})$ uptake was measured over a 10 minute period under conditions in which the uptake was linear. The uptake was measured in triplicates. Non-specific uptakes were determined in the presence of $10 \mu \mathrm{M}$ cytochalasin B and were subtracted from the total uptake. The uptake of 2-DG was terminated 
after 10 minutes by rapidly aspirating off the radioactive incubation medium and washed the cells three times in an ice-cold phosphate-buffered saline (PBS). The radioactivity associated with the cells was determined by cell lysis in $0.05 \mathrm{~N} \mathrm{NaOH}$ with neutralization by the addition of $0.05 \mathrm{~N} \mathrm{HCl}$, followed by liquid scintillation (Beckman, USA). Aliquots from each well were used to determine the protein concentrations using a Bio-Rad protein assay kit (Bio-Rad, USA). Non-specific uptakes and absorption were always $<15 \%$ of the total uptake.

\subsection{Determination of Total Protein Content}

The L6 myotubes were incubated with or without the extracts as indicated in Figures. Then the cells were washed three times with ice-cold PBS and cell lysates were prepared by adding a cell lysis RIPA buffer (Santa cruz, CA) and centrifuging the mixture at $14,000 \mathrm{x}$ g for 15 minutes at $4^{\circ} \mathrm{C}$. The protein content of the supernatant was determined by a Bio-Rad protein assay (Bio-Rad, USA).

\subsection{Gel Electrophoresis and Immunobloting Analysis}

Proteins $(100-200 \mu \mathrm{g})$ were boiled in a Lammeli sample buffer for 5 minutes. The protein was separated in $10 \%$ SDS-PAGE and then transferred to a nitrocellulose transfer membrane (Amersharm, UK). After transfer, the membrane was blocked in $5 \%$ non-fat milk in tris-buffered saline (TBS) and then incubated overnight with primary antibody (1:1000 dilution) in the same buffer. The results were then visualized with a HRP-conjugated goat anti-rabbit (Cell Signaling Technology, MA, USA) and an enhanced chemiluminescence's kit (Amersharm, UK).

\subsection{Isolation of RNA}

After experimental incubation with and without extract, the L6 myotubes were lysed in total RNA isolation reagent Trizol. The proteins were extracted with chloroform and total RNA was precipitated with isopropanol. The RNA precipitate was washed with $70 \%$ ethanol and resuspended in $50 \mu$ of DEPCtreated water.

\subsection{Reverse Transcriptase-Polymerase Chain Reaction (RT-PCR)}

Reverse transcription was carried out to obtain cDNA using 200 units of MMIV reverse transcriptase and $200 \mathrm{ng} / \mu \mathrm{l}$ oligo d[T]18. The primers used were as follows: GLUT-1 sense, 5' -CCC TGC AGT TCG GCT ATA AC-3'; antisense, 5'-AGC ATC TCA AAG GAC TTG CC-3' (298-bp, GeneBank Accession No. BC061873);
GLUT-4, sense, 5'-ATG TGT GGC TGT GCC ATC TT-3'; antisense, 5'-GGT TTC ACC TCC TGC TCT AA-3' (410bp, GeneBank Accession No. D28561); ratGADPH sense, 5'-CTA CCC ACG GCA AGT TCA ACG GCA-3'; antisense, 5'-TCC AGG CGG CAT GTC AGA TCC ACA-3' (598-bp, GeneBank Accession No. NM017008). For each reverse transcription, a PCR reaction with $2 \mu \mathrm{l}$ of the cDNA was carried out in a $20 \mu$ volume reaction using $1 \mathrm{mM}$ dNTP, $1 \mu \mathrm{M}$ of primers, 1 unit of Taq polymerase (New England Bio Labs) in a PCR thermal cycler (MyCycler, BIORAD) for 35 cyclic reactions. The obtained PCR products were electrophoresed on $2 \%$ agarose gels, stained with ethidium bromide and visualized under the UV light. Relative quantification of the RT-PCR products was carried out in an automated gel doc system (Bioimaging System, Syngene, USA).

\subsection{Statistical Analysis}

All results were expressed as mean \pm SE. Statistical comparisons were tested using student's $t$-test and a level for $\mathrm{p}<0.05$ was considered to be significant.

\section{Results}

\subsection{Active Components}

Total phenolic content obtained from ginger extract was $47.60 \pm 1.91$ and $54.68 \pm 1.17 \mathrm{mg}$ gallic acid/g extract and mg tannic acid/g extract, respectively. The HPLC chromatograms of 6-gingerol; the major ginger oleoresin from ginger extract is shown in Table 1. Main peak on retention time 4.3 min was identified as 6 -gingerol was $18.93 \pm 0.17$ $\mathrm{mg} / \mathrm{g}$ dry weight basis.

\subsection{Cytotoxicity Effect of Ginger Extract in L6 Cells}

The cytotoxic effect of the ginger extract was determined at various concentrations ranging from $50-600 \mu \mathrm{g} / \mathrm{ml}$ for 24 hours. As shown in Figure 1, ginger extract did not show any significant toxic effect on L6 myotubes at the concentration below $600 \mu \mathrm{g} / \mathrm{ml}$. Therefore, the concentration at 100-600 $\mu \mathrm{g} / \mathrm{ml}$ of ginger was used for further evaluation of biological activity characterization of glucose transport in more details.

Table 1. HPLC analysis of ginger extract

\begin{tabular}{lcc}
\hline $\begin{array}{c}\text { Active } \\
\text { component }\end{array}$ & $\begin{array}{c}\text { Retention time } \\
(\mathrm{min} .)\end{array}$ & $\begin{array}{c}\text { Content } \\
(\mathrm{mg} / \mathrm{g} \text { dry weight tract })\end{array}$ \\
\hline 6-gingerol & 4.362 & $18.93 \pm 0.17$ \\
6-shogoal & 11.182 & $0.124 \pm 0.005$ \\
Zingerone & 2.728 & $<0.0001$ \\
\hline
\end{tabular}




\subsection{Antidiabetic Activity of Ginger Extract}

The effects of ginger extract on 2-deoxyglucose (2-DG) uptake were dose-and time-dependent (Figure 2). This study was performed to investigate the possible effects of ginger extract on in vitro glucose uptake activity in L6 myotubes, a murine skeletal muscle cell line. At the concentration 200$600 \mu \mathrm{g} / \mathrm{ml}$ of ginger extract showed increase in glucose uptake activity ( $146.22 \pm 4.52 \%$ above basal value, $208.03 \pm 10.65 \%$ above basal value, and 150.00 $\pm 10.00 \%$ above basal value, respectively) (Figure $2 \mathrm{a}$ ). The effect of ginger extract $(400 \mu \mathrm{g} / \mathrm{ml})$ on the 2-DG uptake in $\mathrm{L} 6$ myotubes over $24 \mathrm{~h}$ time course was shown in Figure $2 \mathrm{~b}$. Co-incubation of L6 myotubes with $400 \mu \mathrm{g} / \mathrm{ml}$ of ginger extract resulted in the stimulation of glucose uptake in time-dependent manner. Ginger extract increased glucose uptake in L6 myotubes to the significant levels within $4 \mathrm{~h}$

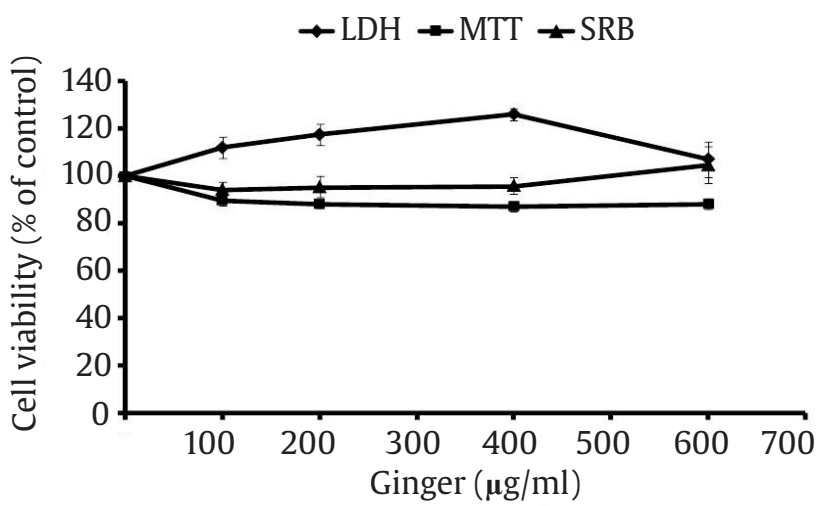

Figure 1. Cell viability curves obtained in the three cytotoxicity assays after treatment of L6 myotubes (A) and 3T3-L1 adipocytes (B) with increasing ginger extract concentrations for $24 \mathrm{~h}$. Data are expressed as percentage of the values found in the respective control cultures

a

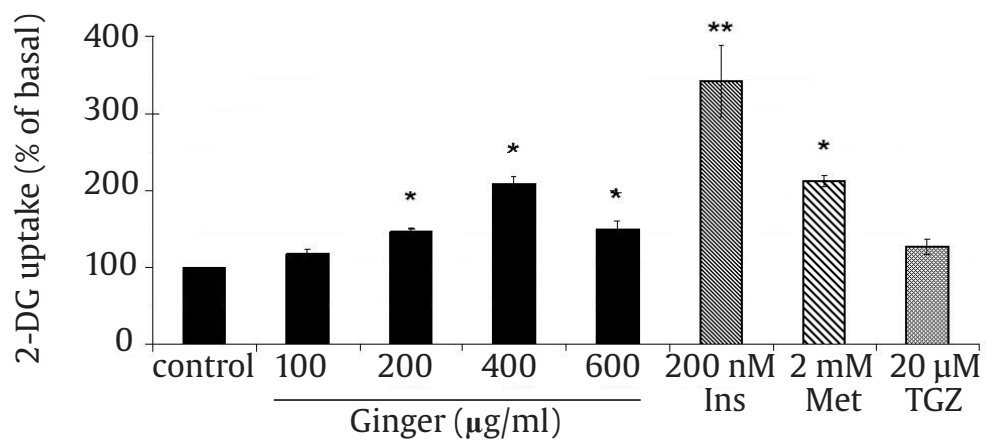

with the maximal stimulation at $24 \mathrm{~h}$ of incubation (197.72 $\pm 13.65 \%$ above basal value; $\mathrm{p}<0.05$ ). These results suggest that the antidiabetic action of ginger rhizome may be mediated through the stimulation of glucose uptake and the potentiation of antidiabetic drugs (Insulin, TGZ and Metformin). Moreover, these effects may require the synthesis of new protein that involve glucose transport especially glucose transporter 1 (GLUT1) and glucose transporter 4 (GLUT 4) in muscle cells. Moreover, to evaluate the effect of heat-inactivate and storage condition on ginger extract-stimulated 2-DG uptake, L6 myotubes were incubated $24 \mathrm{~h}$. with 10-min, 20-min, and 30min heat-inactivated ginger (Figure $3 a$ ) or with ginger extract solution kept at $4^{\circ} \mathrm{C}$ for six months (Figure $3 \mathrm{~b}$ ) and then a 10-min 2-DG uptake was measured. 2-DG uptake activity of ginger extract was not affected by heat-inactivate and storage.

\subsection{The Molecular Mechanistic Actions of Ginger Extract on Insulin Signaling Glucose Transport Pathway}

The enhancement of glucose transport in muscle cells was regulated by two pathways; 1) insulin-dependent signaling pathway and 2) insulin-independent signaling pathway (Figure 4). In insulin-dependent signaling pathway, insulinstimulated glucose transport was mediated via Phosphatidylinositol 3-Kinase (PI3 kinase)-activated GLUT4 translocation and p38MAPK-activated GLUT4 intrinsic activity. In addition, Ras-MAPK-ERK1/2 pathway can activate GLUT1 and GLUT4 expression, resulting in the enhancement of glucose transport in muscle cells. Moreover, the important pathway which is insulin-independent and stimulated both translocation of GLUT4 and expression of GLUT1 and b

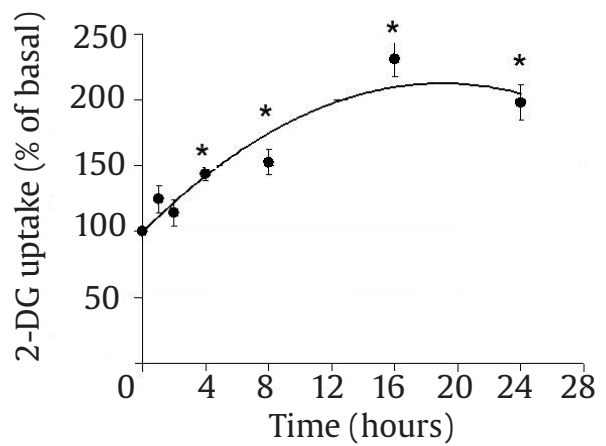

Figure 2. Dose-dependent stimulation of glucose uptake by ginger (a) L6 myotubes were incubated with all indicated concentration of ginger for $24 \mathrm{~h}$. and then a 10-min 2DG uptake was measured. Time-dependent stimulation of glucose uptake by ginger (b) L6 myotubes were incubated with $400 \mu \mathrm{g} / \mathrm{ml}$ of ginger at various timeintervals as indicated in figure and then a 10-min 2DG uptake was measured. The values are mean \pm SE of three independent assays in triplicate, ${ }^{*} \mathrm{p}<0.05$ and ${ }^{* *} \mathrm{p}<0.01$ compared to untreated control group 
GLUT4 is 5'-AMP-activated kinase (AMPK) signaling pathway.

We examined the molecular mechanism of ginger extract on glucose transport. The role of PI3 kinase and AMP kinase were determined by using the specific inhibitors. The enhancement of glucose transport activity was completely abolished by cytochalasin $\mathrm{B}$, suggesting an active proceed of glucose transport. At $400 \mu \mathrm{g} / \mathrm{ml}$, ginger extract significantly enhanced glucose uptake in L6 myotubes after co-culture for $24 \mathrm{~h}$. These effects were inhibited by $3.5 \mu \mathrm{M}$ cycloheximide, a protein synthesis inhibitor, $1 \mu \mathrm{M}$ wortmannin (PI3Kinase inhibitor), and $15 \mathrm{nM}$ rapamycin (mammalian target of rapamycin (mTOR) inhibitor) (Table 2). These results suggest that ginger-induce glucose uptake via the stimulation of both pathways; PI3 kinase and AMP kinase.

Total amount of GLUT1 protein expression in various culture conditions of L6 myotubes was quantified. Figure 5 shows the effect of ginger extract on GLUT1 protein content, GLUT1, and GLUT4 transcription in L6 myotubes. Time dependent effect of ginger-induced GLUT1 protein expression was clearly demonstrated in Figure 5a. Ginger treatment also led to an elevation of GLUT1 mRNA levels. However, GLUT4 transcription did not change when it induced glucose uptake in myotubes (Figure 5b). Therefore, the treatment with $400 \mu \mathrm{g} / \mathrm{ml}$ of ginger extract for 4,8 , and $24 \mathrm{~h}$. Changed the GLUT1 m RNA levels to $1.91 \pm 0.75,2.32 \pm 0.92$, and $2.20 \pm 0.64$ folds of basal, respectively $(\mathrm{p}<0.05)$. We note that the time-dependent effect of ginger on GLUT1 mRNA level was consistent with increased glucose uptake (Figure 2b).

\section{Discussion}
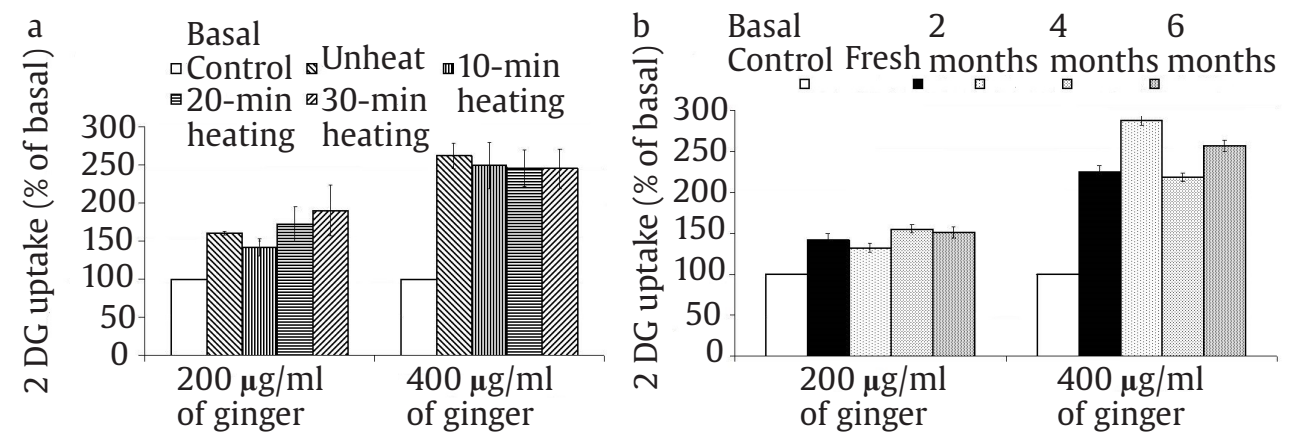

Figure 3. Effect of heat inactivate-ginger (a) and storage condition of ginger on glucose uptake in L6 myotubes. L6 myotubes were incubated for $24 \mathrm{~h}$. with 10-min, 20-min, and 30-min heat-inactivated ginger or ginger extract prepared from freeze dry kept at $4-8^{\circ} \mathrm{C}$ and then a $10-\min 2 \mathrm{DG}$ uptake was measured. The values are mean $\pm \mathrm{SE}$ of three independent assays in triplicate

Table 2. The effect of specific inhibitors on ginger and Ins-stimulated 2-DG uptake in L6-myotubes. ${ }^{*} \mathrm{p}<0.05,{ }^{* *} \mathrm{p}<0.01$ compared to inhibitors-untreated cells

\begin{tabular}{llllcc}
\hline \multirow{2}{*}{ Inhibitor } & \multicolumn{2}{c}{ 2-deoxyglucose uptake (\% of basal) } & \multicolumn{2}{c}{$\%$ stimulation by } \\
\cline { 2 - 6 } & Basal control & $\begin{array}{c}400 \mu \mathrm{\mu g} / \mathrm{ml} \\
\text { ginger }\end{array}$ & $200 \mathrm{nM}$ insulin & Ginger & Insulin \\
\hline None & 100.0 & $211.37 \pm 25.28$ & $341.98 \pm 23.58$ & 111 & 242 \\
$10 \mu \mathrm{M}$ cyto B & $12.18 \pm 1.35$ & $15.28 \pm 2.24$ & $6.36 \pm 3.67$ & 3 & 0 \\
$10 \mu$ MB203580 & $88.96 \pm 3.92$ & $246.72 \pm 29.44$ & $318.97 \pm 25.50$ & 158 & 230 \\
$1 \mu$ M WN & $84.88 \pm 2.13$ & $169.19 \pm 1.51$ & $235.86 \pm 21.21$ & $84^{*}$ & $151^{* *}$ \\
$3.5 \mu$ M CHX & $34.75 \pm 2.00$ & $116.05 \pm 10.29$ & $59.90 \pm 2.50$ & $81^{*}$ & $25^{* *}$ \\
15 nM rapamycin & $67.20 \pm 1.18$ & $121.11 \pm 2.83$ & $113.97 \pm 2.24$ & $54^{* *}$ & $47^{* *}$ \\
\hline
\end{tabular}




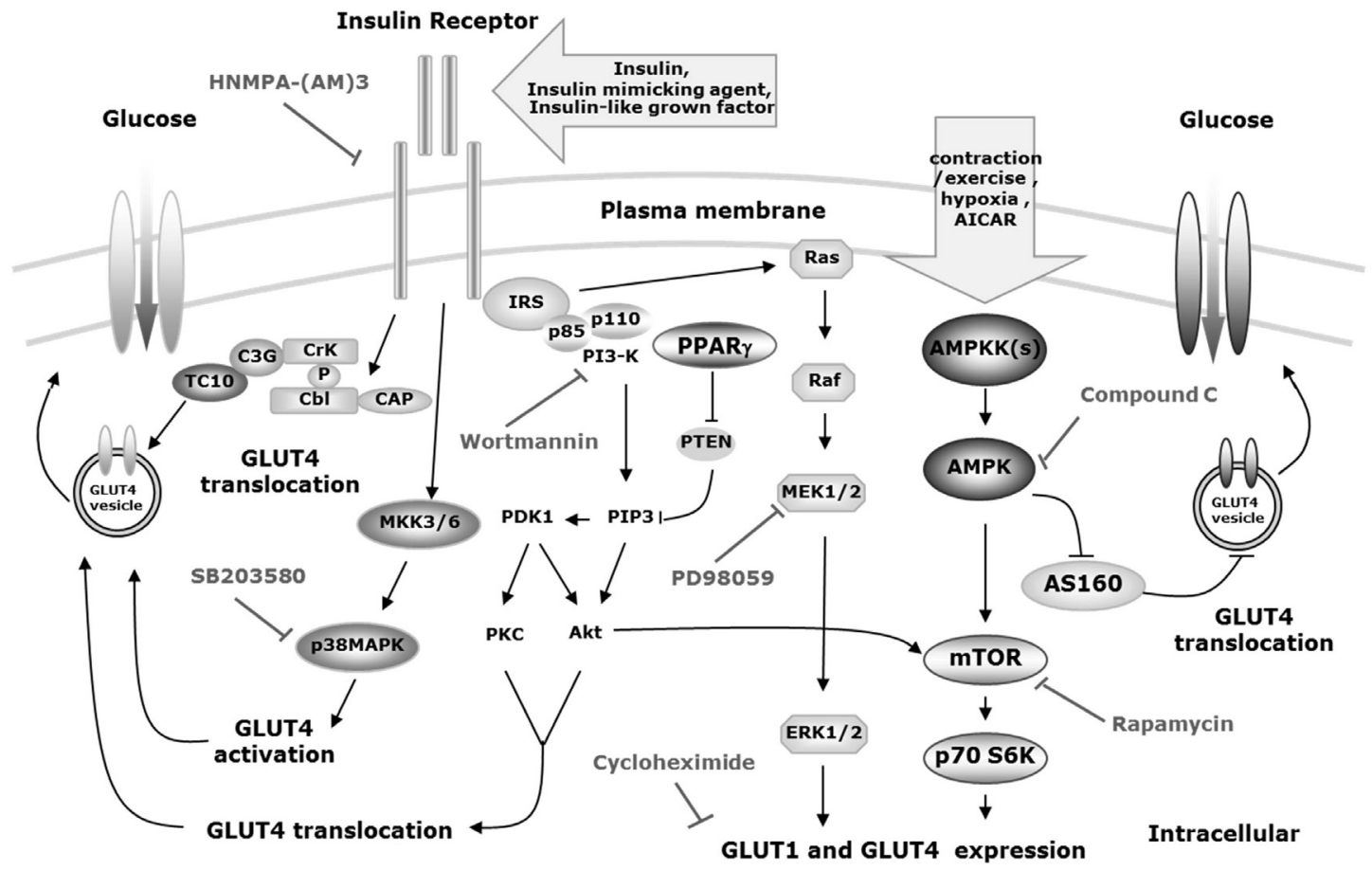

Figure 4. Schematic of pathways regulating glucose transport in adipose tissue and skeletal muscle. Modified from Sakamoto and Goodyear 2002; Furtado et al. 2003; Fujii et al. 2004; Dugani and Klip 2005; Ishiki and Klip 2005

a

GLUT1

Actin

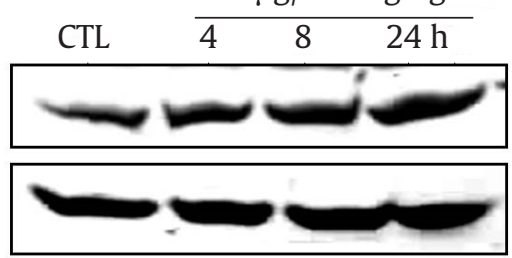

$400 \mu \mathrm{g} / \mathrm{ml}$ of ginger

b

$400 \mathrm{mg} / \mathrm{ml}$ of ginger

CTL $121 \quad 2 \quad 4 \quad 8 \quad 24 \mathrm{~h}$

GLUT1

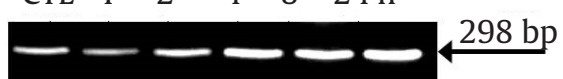

GLUT4

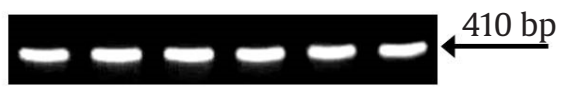

GAPDH

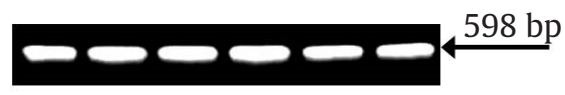

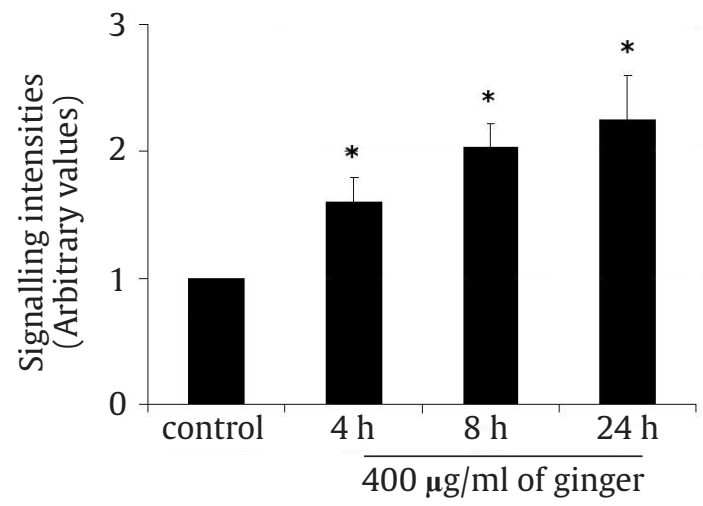

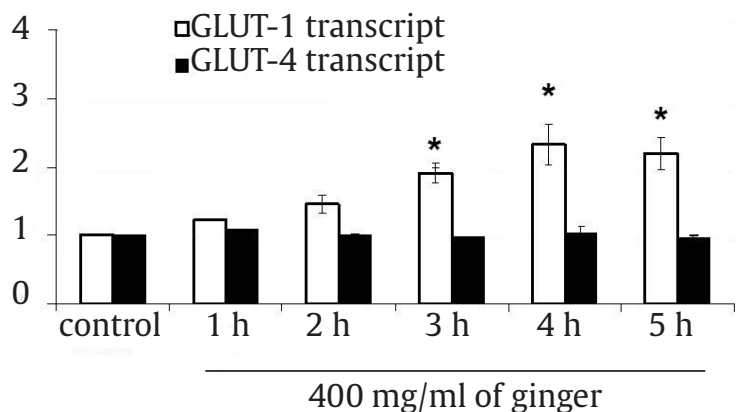

Figure 5. Effect of ginger extract on GLUT1 content (a) and GLUT1 and GLUT4 mRNA levels (b) in L6 myotubes. L6 myotubes were incubated with ginger extract at $400 \mu \mathrm{g} / \mathrm{ml}$ for various time-intervals prior to mRNA preparation with RT-PCR. Total protein content of L6 myotubes were prepared using RIPA lysis buffer and immunoblotting of total cellular protein using anti-GLUT1 antibody. Semi-quantify analysis of GLUT transcript and protein were using scanning densitometry. Bars represent means \pm SE of three independent experiments. ${ }^{*} \mathrm{p}<0.05$ compared to untreated cells 
Z. officinale (ginger) has been reported to possess antihyperglycemic (Akhani et al. 2004; Goyal and Kadnur 2006). To determine whether ginger has any unique and direct extrapancreatic effects on stimulating glucose uptake, we examined the effects of this extract on glucose uptake, and GLUT1 and GLUT4 expression in L6 skeletal muscle cells, an in vitro model of rat skeletal muscle. The current study shows that ginger increased glucose uptake in L6 myotubes for over a $4 \mathrm{~h}$ incubation period and has no effects on short term incubation (30 min.) (Figure $2 b)$. In addition, we showed that the chronic effect of ginger on glucose transport in L6 myotubes was similar to biguanides metformin (Figure 2a). Amira Klip and her co-workers have previously shown that maximal stimulation of glucose uptake was increased by 10-16-h incubation of metformin in L6 muscle cells (Klip et al. 1992). In addition to metformin, the glucose uptake effects of ginger were also similar to troglitazone (TGZ) which exhibited maximum glucose uptake during period of chronic exposure (from 16 to $30 \mathrm{~h}$ ) (Yonemitsu et al. 2001). There are many previous reports on the anti-diabetic effects of medicinal plants. The methanol extract of Pterocarpus marsupium (it is called Prado in Thai) at $20 \mathrm{ng} / \mathrm{ml}$ showed maximum glucose uptake activity (two folds above basal) after a $24 \mathrm{~h}$ incubation period in L6 myotubes. Moreover, this group of investigators identified the lead compound which showed this effect and they postulated that isoflavone from this plant may have activated glucose transport by up-regulation of GLUT4 and PPAR $\gamma$ (Anandharajan et al. 2005). The following year, they reported the effects of medicinal plants in a series of targets in insulin signaling cascade. Both Aegles marmelos (Matoom in Thai) and Syzygium cumini (Wha in Thai) were studied in detail using an in vitro model for their peripheral effects. At levels of 100 $\mathrm{ng} / \mathrm{ml}$ of methanol extracts, these plants increased glucose uptake into L6 myotubes by two folds above basal after a $24 \mathrm{~h}$ incubation period. The previous observation concluded that these plants activate glucose transport via activation of GLUT4, PI3 kinase and PPAR $\gamma$ (Anandharajan et al. 2006). M. charantia showed the stimulation of glucose transport effects in L6 myotubes (Cummings et al. 2004). This is the first known report on the mechanism of hypoglycaemic action of $M$. charantia in vitro. At $5 \mu \mathrm{g} / \mathrm{ml}$ of $M$. charantia fruit juice increased approximately two folds of glucose uptake from a basal uptake after a $6 \mathrm{~h}$ incubation period. These results are, in fact, compatible with our findings.
Z. officinale activates glucose uptake via GLUT1 upregulation. The onset of augmentation of the basal glucose transport by ginger was slow. This suggests that the effects may require the synthesis of new proteins that are involved in glucose transport especially GLUT1 and GLUT4 transporters in muscle cells. CHX can prevent the ginger-induced 2-DG uptake. Furthermore, our results showed that ginger did increase the expression of GLUT1 in L6 myotubes both in mRNA and protein levels (Figure 5). Thus, the increase of glucose uptake with time apparently reflects the ongoing synthesis of GLUT1 protein or a new protein that affects the GLUT1 protein expression. Therefore, the main mechanism of the enhancement effect by ginger on glucose transport is involved in the activation of the GLUT1 expression. In our present study, we propose that ginger stimulates at least two pathways to promote GLUT1 expression in L6 myotubes. Previous studies have shown that GLUT1 expression in both L6 myotubes and 3T3-L1 adipocytes is regulated by PI3/PKB (Akt)/mTOR/4E-BP1 (Taha et al. 1995; Somwar et al. 1998; Taha et al. 1999). Moreover, several researchers have reported that the stimulation of AMPK activity is associated with the enhancement of GLUT1-glucose transporter (Abbud et al. 2000; Barnes et al. 2002; Jing and Ismail-Beigi 2006). In this study, we found that increasing glucose uptake activity by ginger was abolished by wortmannin (PI3 kinase inhibitor) and rapamycin (AMPK kinase inhibitor) (Table 2). Therefore, both pathways; PI3 kinase and AMP kinase may regulated ginger-induced glucose uptake in L6 myotubes.

The current study also reported that 6 -gingerol was the most abundant among recognized components which reemphasize the role of this component for probable health benefits of ginger. This result is consistent with the findings of Sanwal et al. (2010) and Schwertner and Rios (2007). In recent years, the pungent phenolic gingerol constituents were identified as the major active compounds in the ginger extract enhancing glucose uptake (Li et al. 2012). In addition, they found that (S)-[6]-Gingerol extracted from ethyl acetate fraction was the most abundant component among the gingerols, however, (S)-[8]-gingerol was the most potent on glucose uptake and an increase in surface distribution of GLUT4 protein on the L6 myotube plasma membrane. Hence, gingerol, a pungent principle of the ginger extract, may play a significant role on glucose transport in L6 myotubes. However, ginger also contains other various constituents such 
as alkaloids and phenolic compounds. Therefore, there should be future research about the effectiveness of these anti-diabetic components and its mechanisms.

In conclusion, $Z$. officinale Roscoe rhizome extract increase glucose transport activity of L6 myotubes by enhancing GLUT1 expression, the results of PI3Kinase and AMPK stimulation.

\section{Acknowledgements}

This work was supported by grants number MRG5480089 from the Thailand Research Found (TRF), the Commission of Higher Education (CHE), and Thaksin University (TSU).

\section{Conflict of Interest}

The authors report no conflict of interest.

\section{References}

Abbud W et al. 2000. Stimulation of AMP-activated protein kinase (AMPK) is associated with enhancement of Glut1-mediated glucose transport. Arch Biochem Biophys 380:347-352.

Akhani SP et al. 2004. Anti-diabetic activity of Zingiber officinale in streptozotocin-induced type I diabetic rats. J Pharm Pharmacol 56:101-105.

Al-Amin ZM et al. 2006. Anti-diabetic and hypolipidaemic properties of ginger (Zingiber officinale) in streptozotocin-induced diabetic rats. $\mathrm{Br} J \mathrm{Nutr}$ 96:660-666.

Anandharajan R et al. 2005. Upregulation of Glut-4 and PPAR gamma by an isoflavone from Pterocarpus marsupium on L6 myotubes: a possible mechanism of action. $J$ Ethnopharmacol 97:253-260.

Anandharajan R et al. 2006. In vitro glucose uptake activity of Aegles marmelos and Syzygium cumini by activation of Glut-4, PI3 kinase and PPARgamma in L6 myotubes. Phytomedicine 13:434-441.

Ball SW et al. 2002. A fluorescent compound for glucose uptake measurements in isolated rat cardiomyocytes. Can J Physiol Pharmacol 80:205-209.

Barnes K et al. 2002. Activation of GLUT1 by metabolic and osmotic stress: potential involvement of AMP activated protein kinase (AMPK). J Cell Sci 115:24332442.

Bhandari U et al. 2005. Effect of ethanolic extract of Zingiber officinale on dyslipidaemia in diabetic rats.J Ethnopharmacol 97:227-230.

Cummings E et al. 2004. Momordica charantia fruit juice stimulates glucose and amino acid uptakes in L6 myotubes. Mol Cell Biochem 261:99-104.

Dohm GL et al. 1988. An in vitro human muscle preparation suitable for metabolic studies: decreased insulin stimulation of glucose transport in muscle from morbidly obese and diabetic subjects. J Clin Invest 82:486-494.
Dugani CB, Klip A. 2005. Glucose transporter 4: cycling, compartments and controversies. EMBO Rep 6:11371142.

Fujii N et al. 2004. Regulation of glucose transport by the AMP-activated protein kinase. Proc Nutr Soc 63:205210.

Furtado LM et al. 2003. GLUT4 activation: thoughts on possible mechanisms. Acta Physiol Scand 178:287296.

Goyal RK, Kadnur SV. 2006. Beneficial effects of Zingiber officinale on goldthioglucose induced obesity. Fitoterapia 77:160-163.

Ishiki M, Klip A 2005. Minireview: recent developments in the regulation of glucose transporter-4 traffic: new signals, locations, and partners. Endocrinology 146:5071-5078.

Jing M, Ismail-Beigi F. 2006. Role of 5'-AMP-activated protein kinase in stimulation of glucose transport in response to inhibition of oxidative phosphorylation. Am J Physiol Cell Physiol 290:484-491.

Klip A et al. 1984. Induction of sugar uptake response to insulin by serum depletion in fusing $L 6$ myoblasts. Am J Physiol 247:291-296.

Klip A et al. 1992. Stimulation of hexose transport by metformin in L6 muscle cells in culture. Endocrinology 130:2535-2544.

Li Y et al. 2012. Gingerols of Zingiber officinale enhance glucose uptake by increasing cell surface GLUT4 in cultured L6 myotubes. Planta Med 78:1549-1555.

Miliauskus G et al. 2004. Screening of radical scavenging activity of some medicinal and aromatic plant extracts. Food Chem 85:231-237.

Mojani MS et al. 2014. Assessment of bioactive compounds, nutritional composition and antioxidant activity of Malaysian young ginger (Zingiber officinale Roscoe). Int J Food Res 21:1931-1935.

Mustafa T, Srivastava KC. 1990. Ginger (Zingiber officinale) in migraine headache. J Ethnopharmacol 29:267-273.

Noipha K et al. 2008. In vitro glucose uptake activity of Tinospora crispa in skeletal muscle cells. Asian Biomed 2:415-420.

Ojewole JA. 2006. Analgesic, antiinflammatory and hypoglycaemic effects of ethanol extract of Zingiber officinale (Roscoe) rhizomes (Zingiberaceae) in mice and rats. Phytother Res 20:764-772.

Papazisis KT et al. 1997. Optimization of the sulforhodamine B colorimetric assay. J Immunol Methods 208:151158.

Sakamoto K, Goodyear LJ. 2002. Invited review: intracellular signaling in contracting skeletal muscle. J Appl Physiol 93:369-383.

Sanwal SK et al. 2010. Antioxidant phytochemicals and gingerol content in diploid and tetraploid clones of ginger (Zingiber officinale Roscoe). Scientia Horticulturae 124:280-285.

Schwertner HA, Rios DC. 2007. High-performance liquid chromatographic analysis of 6-gingerol, 8-gingerol, 10-gingerol, and 6-shogaol in ginger containing dietary supplements, spices, teas, and beverages. $J$ Chromatograp B 856:41-47. 
Shen CL et al. 2005. Comparative effects of ginger root (Zingiber officinale Rosc.) on the production of inflammatory mediators in normal and osteoarthrotic sow chondrocytes. J Med Food 8:149-153.

Shukla Y, Singh M. 2007. Cancer preventive properties of ginger: a brief review. Food Chem Toxicol 45:683-690.

Somwar R et al. 1998. Temporal activation of p70 S6 kinase and Akt1 byinsulin: PI 3-kinase-dependent and independent mechanisms. Am J Physiol 275:618-625.

Taha C et al. 1999. Opposite translational control of GLUT1 and GLUT4 glucose transporter mRNAs in response to insulin. Role of mammalian target of rapamycin, protein kinase b, and phosphatidylinositol 3-kinase in GLUT1 mRNA translation. J Biol Chem 274:3308533091.
Taha C et al. 1995. The insulin-dependent biosynthesis of GLUT1 and GLUT3 glucose transporters in L6 muscle cells is mediated by distinct pathways. Roles of p21 ras and pp70 S6 kinase. J Biol Chem 270:24678-24681.

Thomson M et al. 2002. The use of ginger (Zingiber officinale Rosc.) as a potential anti-inflammatory and antithrombotic agent. Prostaglandins Leukot Essent Fatty Acids 67:475-478.

Yonemitsu S et al. 2001. Troglitazone induces GLUT4 translocation in L6 myotubes. Diabetes 50:1093-1101. 